\title{
Consequências diretas da má conservação das estradas com vistas ao consumo de combustível, velocidade média e desgaste dos pneumáticos
}

\author{
Eduardo Nunes de Magalhães \\ Engenheiro Agrícola e Engenheiro de Segurança do Trabalho. \\ Professor do Ensino Básico Técnico e Tecnológico. Instituto Federal do Triângulo \\ Mineiro Campus Curso Técnico em Mineração. Patos de Minas. MG \\ $\triangle$ eduardonunes@iftm.edu.br \\ Paulo Caetano da Silva \\ Aluno do Ensino Básico Técnico e Tecnológico. \\ Curso Técnico em Mineração. Instituto Federal do Triângulo Mineiro \\ Campus Patos de Minas, MG \\ $\bowtie$ paulocaetano@yahoo.com.br
}

Recebido em 2 de agosto de 2018

Aceito em 15 de novembro de 2018

\begin{abstract}
Resumo:
O Brasil possui uma enorme extensão territorial e, $60 \%$ do transporte de suas cargas fluem pelas rodovias federais, estaduais e municipais. Sendo assim, o transporte de carga gira um negócio bilionário em todo o país capaz de promover o desenvolvimento. Contudo, na mesma medida da importância dessa modalidade de transporte está o descaso da classe governante do país com a construção e manutenção das estradas brasileiras. Isso tem promovido um incremento nos custos do transporte e, consequentemente, na cadeia produtiva de vários produtos, impactando diretamente seus preços. Existem poucos estudos sobre o impacto direto da má conservação das estradas na economia e grande parte do que existe é feito pela Confederação Nacional dos Transportes- CNT. Essa falta de dados sobre o setor se deve ora pela dificuldade no controle das variáveis, ora pela complexidade do assunto. $O$ presente estudo teve por objetivo analisar três parâmetros fundamentais que é o consumo de combustível $(\mathrm{Km} / \mathrm{L})$, velocidade média $(\mathrm{Km} / \mathrm{h})$ e desgaste dos pneumáticos. Para isso, foi realizada a coleta dos dados em 21 viagens, em duas rotas conhecidas, a saber: Patos de MinasMG a Fortaleza-CE e Patos de Minas-MG a Santa Maria- RS. A primeira possui condições piores de tráfego em mais de $60 \%$ do trecho, tais como pista irregular e com buracos, má sinalização, falta de acostamento, dentre outras. Os resultados demonstram haver diferenças estatísticas entre as rotas para os três parâmetros estudados, sendo que os mais negativos foram encontrados nos trechos onde há piores condições de conservação.

Palavras-chave: Rodovias, Conservação, Anti Economia.
\end{abstract}

\section{Direct consequences of major road conservation with a view to fuel consumption, average speed and tires wear}

\begin{abstract}
:
Brazil has a huge territorial extension and $60 \%$ of the transportation of its cargo flows through federal, state and municipal highways. Thus, freight transportation is a billion dollar business in the whole country capable of promoting development. However, to the same extent of the importance of this modality of transport is the neglect of the ruling class of the country with the construction and maintenance of the Brazilian roads. This has promoted an increase in transport costs and, consequently, in the productive chain of several products, directly impacting their prices. There are few studies on the direct impact of poor road maintenance on the economy, and much of what is done
\end{abstract}


by the National Confederation of Transport-CNT. This lack of data on the sector is due to the difficulty in controlling the variables, or the complexity of the subject. The objective of the present study was to analyze three fundamental parameters: fuel consumption $(\mathrm{Km} / \mathrm{L})$, average speed $(\mathrm{km} / \mathrm{h})$ and tire wear. For this, the data were collected in 21 trips, in two known routes, namely: Patos de Minas-MG to Fortaleza-CE and Patos de Minas-MG to Santa Maria-RS. The first one has worse traffic conditions in more than $60 \%$ of the stretch, such as irregular track and with holes, bad signaling, lack of roadway, among others. The results show statistical differences between the routes for the three studied parameters, being that the most negative ones were found in the stretches where there are worse conservation conditions.

Keywords: Highways, Conservation, Anti Economy.

\section{Consecuencias diretas de la má conservación de las carreteras con vistas al consumo de combustible, velocidad media y desgaste de los neumáticos}

\section{Resumen:}

Brasil posee una enorme extensión territorial y el $60 \%$ del transporte de sus cargas fluye por las carreteras federales, estatales y municipales. Siendo así, el transporte de carga gira un negocio multimillonario en todo el país capaz de promover el desarrollo. Sin embargo, en la misma medida de la importancia de esa modalidad de transporte está el descuido de la clase gobernante del país con la construcción y mantenimiento de las carreteras brasileñas. Esto ha promovido un incremento en los costos del transporte y, consecuentemente, en la cadena productiva de varios productos, impactando directamente sus precios. Hay pocos estudios sobre el impacto directo de la mala conservación de las carreteras en la economía y gran parte de lo que existe es hecho por la Confederación Nacional de los Transportes CNT. Esta falta de datos sobre el sector se debe a la dificultad en el control de las variables, ora por la complejidad del asunto. El presente estudio tuvo por objetivo analizar tres parámetros fundamentales que es el consumo de combustible $(\mathrm{Km} / \mathrm{L})$, velocidad media $(\mathrm{Km} / \mathrm{h})$ y desgaste de los neumáticos. Para ello, se realizó la recolección de los datos en 21 viajes, en dos rutas conocidas, a saber: Patos de Minas Gerais a Fortaleza-CE y Patos de Minas Gerais a Santa Maria-RS. La primera tiene condiciones peores de tráfico en más del $60 \%$ del tramo, tales como pista irregular y con agujeros, mala señalización, falta de acoso, entre otras. Los resultados demuestran que existen diferencias estadísticas entre las rutas para los tres parámetros estudiados, que los más negativos fueron encontrados en los tramos donde hay peores condiciones de conservación.

Palabras clave: Carreteras, Conservación, Anti-Economía.

\section{INTRODUÇÃO}

Países como a Rússia, Canadá, Austrália e Estados Unidos tem realizado grandes investimentos em transporte ferroviário, hidroviário e aéreo diminuindo drasticamente problemas relacionados ao transporte de cargas em rodovias por caminhões, gerando malhas rodoviárias com qualidades superiores e mitigação de problemas tais como acidentes e mortes (UOL, 2017). Essa tendência já não tem sido acompanhada pela América Latina onde países como Brasil utilizam mais de 60\% do Transporte de Cargas por rodovias, sendo que a maioria delas encontra-se em péssimo estado de conservação. Segundo a Confederação Nacional dos Transportes- CNT (2017), o Transportes de cargas no Brasil, realizada pelo seu Centro de Estudos em Logística demonstrou que, 61,8\% das estradas brasileiras apresentam 
algum tipo de deficiência (33,6\% regular, 20,1\% ruim e 8,1\% péssimo). Na pesquisa foram identificados $52.911 \mathrm{Km}$, onde 50\% possuem problemas de pavimento, sendo 34\% regular, 13,2\% ruim e 2,8\% péssimo. Nas rodovias sob gestão pública, 29,6\% foram consideradas ótimas ou boas e $70,4 \%$, regulares, ruins ou péssimas enquanto as rodovias pertencentes a iniciativa privada $74,4 \%$ foram consideradas boas ou ótimas.

Das rodovias públicas, 94,3\% dos trechos analisados são compostos por pistas simples de mão dupla; $0,6 \%$, por pistas duplas com canteiro central; $1,3 \%$, por pistas duplas com barreira ou faixa central; e 0,2\%, por pistas simples de mão única. 49,2\% das rodovias têm acostamento, enquanto 50,8\% não contam com esse recurso. Além disso, nestes 49,2\%, apenas 87,3\% destes possuem pavimento perfeito. Em 17,6\% da extensão avaliada não foram identificadas placas de advertência nem estruturas de proteção lateral suficientes. Em 26,8\% dos casos, há placas ilegíveis ou desgastadas.

Ainda segundo a CNT, é possível observar que as estradas ainda contam com muitos pontos de precariedade, o que interfere diretamente na eficiência dos caminhões e se reflete nos custos de viagens e até na emissão de poluentes. Buracos nas pistas, ondulações e outros problemas apresentados nas rodovias obrigam os motoristas a reduzir a marcha com frequência durante a viagem, o que aumenta de modo significativo o consumo de combustível e logicamente o desgaste dos pneus CNT (2017).

Os gastos gerados por aumento na manutenção dos veículos não possuem impacto apenas para os proprietários, mas para toda a sociedade, uma vez que estes custos aumentam o preço do frete e, consequentemente, influenciam os preços finais dos produtos. Essa afirmação é embasada no fato de que no Brasil o transporte rodoviário movimenta cerca de $60 \%$ do transporte de cargas nacionais, enquanto em países como os Estados Unidos usam apenas $26 \%$, a Austrália $24 \%$ e a China apenas $8 \%$. Em contrapartida, a malha rodoviária brasileira corresponde a 69\% daquela existente na China, 55\% do Canadá, 45\% do México e 6\% dos Estados Unidos. (Centro de Estudos em Logística - CEL et al., 2017).

A região Nordeste é a que detém as piores condições da malha rodoviária em todo o País, fato esse que compromete o desenvolvimento e as possibilidades de maior integração econômica com as demais regiões (CNT,2017). 


\section{MATERIAIS E MÉTODOS}

Não existem muitas pesquisas no Brasil sobre as consequências diretas da falta de conservação das estradas, no que diz respeito ao consumo de combustível ou prejuízos advindos da manutenção de veículos ou de seus pneumáticos. Desta forma, para a mensuração do consumo de combustível, foram realizados levantamento do consumo médio nos caminhões através do computador de bordo, utilizando o instrumento através da coleta de dados no computador, após cada viagem. Dados como quilometragem, percurso, consumo médio, peso da carga, velocidade média, tempo gasto e levantamento das condições ambientais e das estradas, eram coletados a cada viagem. Quanto ao percurso, foram computadas 21 viagens no total durante 2017 para cada uma das rotas discriminadas, conforme Figura 1.

Figura 1: Rotas pesquisadas.

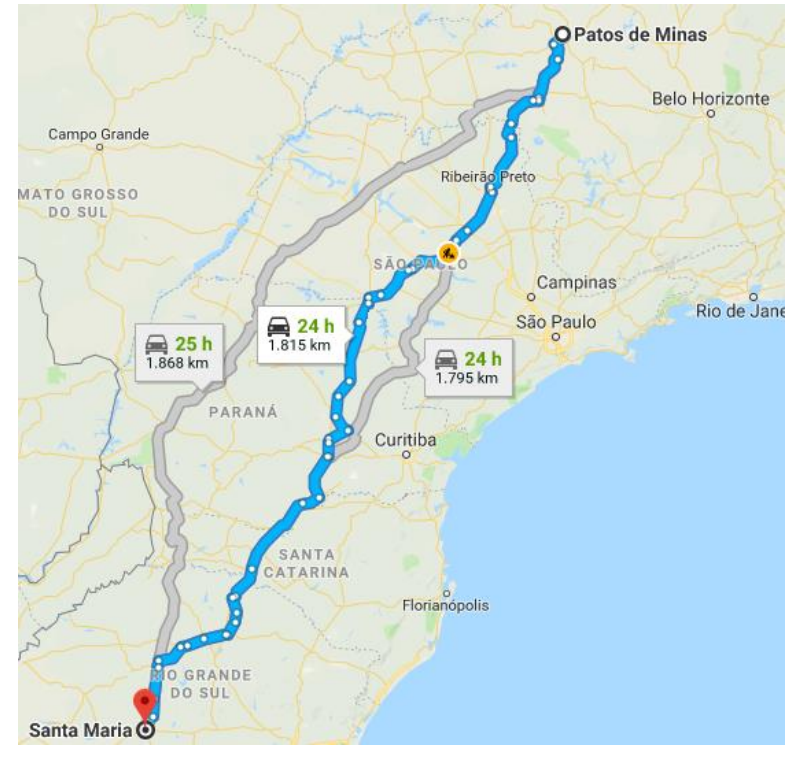

Trajeto a) Patos de Minas- MG a Santa MariaRS

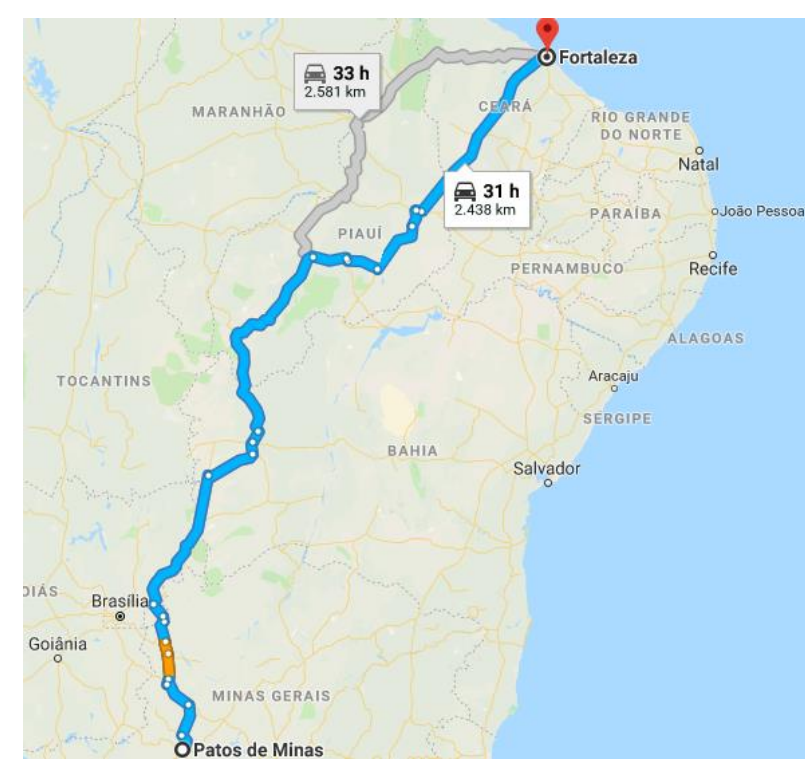

Trajeto b) Patos de Minas -MG a Fortaleza CE

Fonte: Google Maps, 2018.

Cada rota foi percorrida pelo mesmo modelo de caminhão, o Volvo FH 420 6x2, todos fabricados em 2006, com implemento bitrem-graneleiro, 7 eixos no conjunto e Peso Bruto Total Combinado - PBTC (peso do cavalo + o peso do semi-reboque + o peso da carga transportada) de $59 \mathrm{t}$. 
As viagens na rota (a) foram realizadas em janeiro de 2017 e outubro de 2017 no trecho e na rota (b), entre março de 2017 e agosto de 2017, sendo os trechos conforme Tabela 1.

Tabela 1- Classificação do estado geral dos pavimentos para as rotas (a) e (b).

\begin{tabular}{|c|c|c|c|c|c|c|}
\hline \multirow{3}{*}{ Rodovia } & \multicolumn{5}{|c|}{ Patos de Minas-MG/ Santa Maria RS } & \multirow{3}{*}{ Estado Gera } \\
\hline & \multicolumn{5}{|c|}{ Condição geral do pavimento \% } & \\
\hline & Ótimo & Bom & Regular & Ruim & Péssimo & \\
\hline BR 365 & 1,7 & 41 & 53,8 & 3,5 & - & Regular \\
\hline BR 146 & - & 55,3 & 33,5 & 9,3 & 1,9 & Regular \\
\hline BR 050 & 32,7 & 56,3 & 5,8 & 5,2 & - & Bom \\
\hline BR 369 & 11,9 & 37,2 & 33,5 & 15,8 & 1,6 & Regular \\
\hline BR 153 & 2,8 & 40,8 & 42,9 & 8,4 & 5,1 & Regular \\
\hline BR 376 & 24,4 & 35,6 & 27,9 & 12,1 & - & Bom \\
\hline BR 373 & 9,4 & 50,6 & 34,8 & 5,2 & - & Bom \\
\hline \multirow[t]{2}{*}{ BR 158} & 0,7 & 24,2 & 42 & 23,5 & 9,6 & Regular \\
\hline & \multicolumn{5}{|c|}{ Patos de Minas-MG/ Fortaleza-CE } & \\
\hline BR 365 & 1,7 & 41 & 53,8 & 3,5 & - & Regular \\
\hline BR 122 & 5 & 20,8 & 41,5 & 27,2 & 5,5 & Regular \\
\hline BR 030 & 0,5 & 18,3 & 25,4 & 48,7 & 7,1 & Regular \\
\hline BA 026 & & & $* 1$ & & & Regular \\
\hline BA 142 & & & $* 1$ & & & Péssimo \\
\hline BA 407 & & & $* 1$ & & & Ótimo \\
\hline BA 028 & & & $* 1$ & & & Regular \\
\hline CE 371 & & & $* 1$ & & & Péssimo \\
\hline CE 138 & & & $* 1$ & & & Péssimo \\
\hline
\end{tabular}

Fonte: Pesquisa CNT 2017 e fonte própria.

${ }^{* 1}$ Dados não apresentados pela CNT 2017, porém condição geral atestada na pesquisa.

Estimativa dos parâmetros. 


\section{a) Consumo médio de combustível}

Foi obtido através dos dados retirados do computador de bordo do caminhão. 0 cálculo eletrônico foi realizado levando-se em conta a quilometragem total percorrida e consumo total de combustível, auferindo-se o consumo médio em $\mathrm{km}$ por litros (Tabela 2). Os dados foram descarregados ao final de cada viagem em um computador padrão. Uma vez que, apenas cerca de $1 \%$ do percurso total é realizado em área urbana, essa variável foi desconsiderada para o estudo.

\section{b) Tempo médio de viagem}

Da mesma forma que o consumo médio, o tempo médio de viagem foi retirado a partir do computador de bordo (Tabela 2).

\section{c) Gasto com pneumáticos}

A cada viagem realizada era feita uma inspeção nos pneumáticos a procura de informações (conforme imagens do anexo 1) a fim de não apenas quantificar mas também de classificar o dano. Era realizada uma entrevista com o caminhoneiro para descrição das condições das estradas e danos aos pneus, onde foi utilizado o referido anexo como base. Porém, devido ao grande número de qualificações de danos possíveis, as respostas foram agrupadas de acordo com a Tabela 5, para facilitar a compreensão acerca do assunto.

Para todas as variáveis estudadas efetuou-se análise de variância e comparação de médias, através do teste de Tukey a $5 \%$ de probabilidade, utilizando-se o programa estatístico Sisvar 5.6 (Ferreira, 2000). A análise de variância é um procedimento utilizado para comparar tratamentos. Existem muitas variações devido aos diferentes tipos de experimentos que podem ser realizados. Para testar a hipótese Ho, utiliza-se o teste F que leva em consideração a soma dos quadrados das variáveis estudadas. Convém lembrar que esse teste é válido se os pressupostos assumidos para os erros do modelo estiverem satisfeitos. Pode-se mostrar que o quociente QMTrat/QMRes tem distribuição F com (I - 1) e I (J - 1 ) graus de liberdade, supondo que, yij são variáveis aleatórias independentes, todos os tratamentos têm variâncias iguais a $\sigma 2 \mathrm{e}$ Yij $\sim \mathrm{N}\left(\mu \mathrm{i}, \sigma^{2}\right)$. Por esses motivos, os pressupostos da ANOVA devem ser testados 
ou avaliados em qualquer análise S e Fcalculado> Ftabelado, rejeitamos a hipótese de nulidade H0, ou seja, existem evidências de diferença significativa entre pelo menos um par de médias de tratamentos, ao nível $\alpha$ de significância escolhido. Caso contrário, não se rejeitamos a hipótese de nulidade Ho, ou seja, não ha' evidências de diferença significativa entre tratamentos, ao nível $\alpha$ de significância escolhido. Outra maneira de avaliar a significância da estatística F é utilizando o p-valor. S e o p-valor< $\alpha$, rejeitamos a hipótese de nulidade H0. Caso contrário, não se rejeitamos a hipótese de nulidade H0, ou seja, não há evidências de diferenças significativas entre os tratamentos, ao nível $\alpha$ de significância escolhido.

Após concluirmos que existe diferença, significativa entre tratamentos, por meio do teste $F$, podemos estar interessados em avaliar a magnitude destas diferenças, utilizando um teste de comparações múltiplas. $O$ teste de Tukey permite testar qualquer contraste, sempre, entre duas médias de tratamentos, ou seja, não permite comparar grupos entre si. O teste baseia-se na Diferença Mínima Significativa (DMS ) $\Delta$. A estatística do teste é dada da seguinte forma:

$$
\Delta=q \sqrt{\frac{Q M \operatorname{Res}}{r}},
$$

em que, q e a amplitude total studentizada, tabelada, QMRes é o quadrado médio do resíduo, e r é o número de repetições. O valor de q depende do número de tratamentos e do número de graus de liberdade do resíduo. Também, em um teste de comparações de médias, deve-se determinar um nível de significância $\alpha$ para o teste. Normalmente, utiliza-se o nível de $5 \%$ ou $1 \%$ de significância. Como o teste de Tukey é, de certa forma, independente do teste F, é possível que, mesmo sendo significativo o valor de Fcalculado, não se encontrem diferenças significativas entre contrastes de médias. Aplicando o teste de Tukey às médias dos tratamentos. Utilizar-se-á o método de letras para exemplificar o uso do teste, mas existem outras maneiras de representação como, por exemplo, o uso de tabelas ou barras. Inicialmente, ordenamos as médias de forma crescente ou decrescente, para facilitar as comparações. Colocamos uma letra do alfabeto na primeira média (normalmente a letra' a') e, em seguida, comparamos a diferença com as médias seguintes. $\mathrm{S}$ e a diferença for superior ao valor de $\Delta(5 \%)=0,06696$, a diferença entre duas médias será considerada significativa. A diferença entre duas médias é representada pela presença de letras diferentes. Temos que, 
médias de crescimento, seguidas de letras iguais, não diferem significativamente entre si, pelo teste de Tukey ao nível de 5\% de probabilidade.

\section{RESULTADOS}

Os dados de consumo demonstraram que não houve diferenças estatísticas entre as viagens para nenhuma das rotas, ou seja, apesar de ter havido uma diferença matemática entre elas nos quesitos velocidade média e consumo, não ocorreram diferenças estatísticas, demonstrando pouca dispersão dos dados (Figura 2) em relação as médias para as rotas estudadas (Tabela 2).

Apesar de ter havido apenas diferenças matemáticas nas rotas para os dois parâmetros estudados, houve diferenças estatísticas entre as rotas no que tange a velocidade média e o consumo de combustível (Tabela 3). A rota Patos de Minas-MG a Fortaleza-CE apresentou menor velocidade média e maior consumo quando comparada a rota Patos de Minas-MG a Santa Maria-RS o que confirma a hipótese de que o estado de conservação das estradas ( Tabela 01) está diretamente ligada a estes fatores já que o trecho Patos de Minas MG a Fortaleza CE possui piores condições de pavimento. Os dois parâmetros apresentaram aproximadamente $9 \%$, ou seja, a rota Patos de Minas-MG a Fortaleza-CE consumiu aproximadamente $9 \%$ a mais de combustível e de tempo de viagem se comparada com a rota Patos de Minas-MG a Santa Maria-RS.

Figura 2- Dados de dispersão dos dados de velocidade média e consumo médio para cada uma das viagens realizadas. 


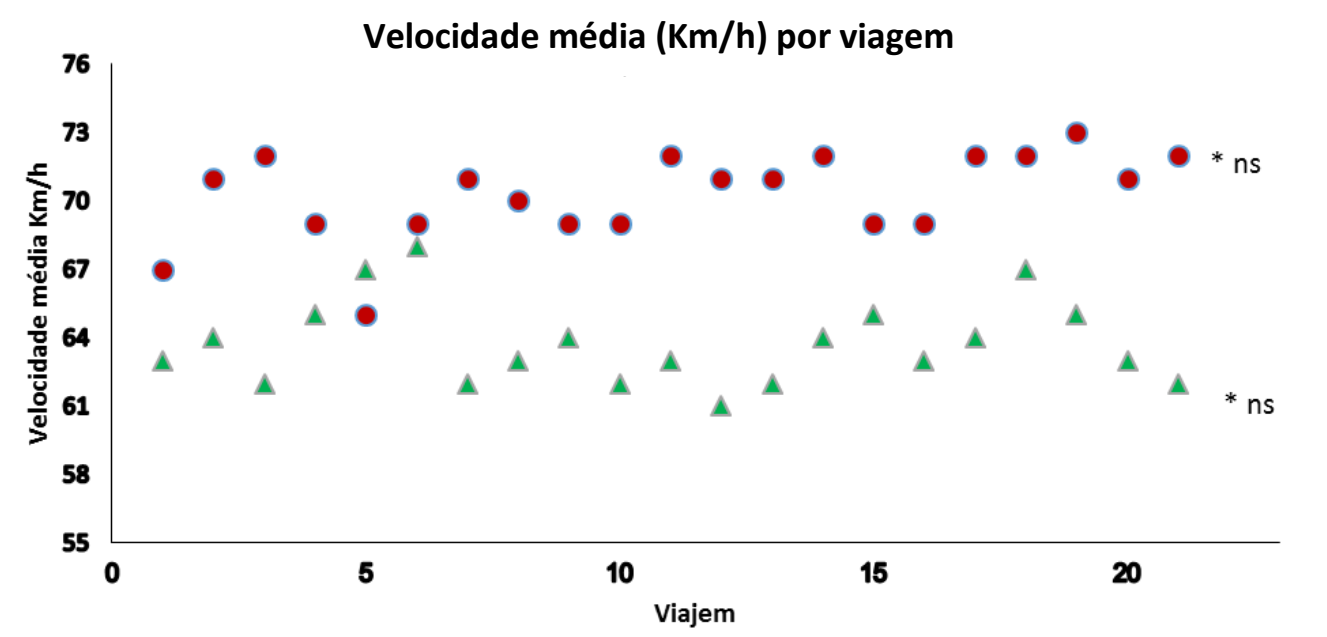

- Patos de Minas MG - Santa Maria RS * ns P>0,05

$\triangle$ Patos de Minas MG - Fortaleza CE * ns P>0,05

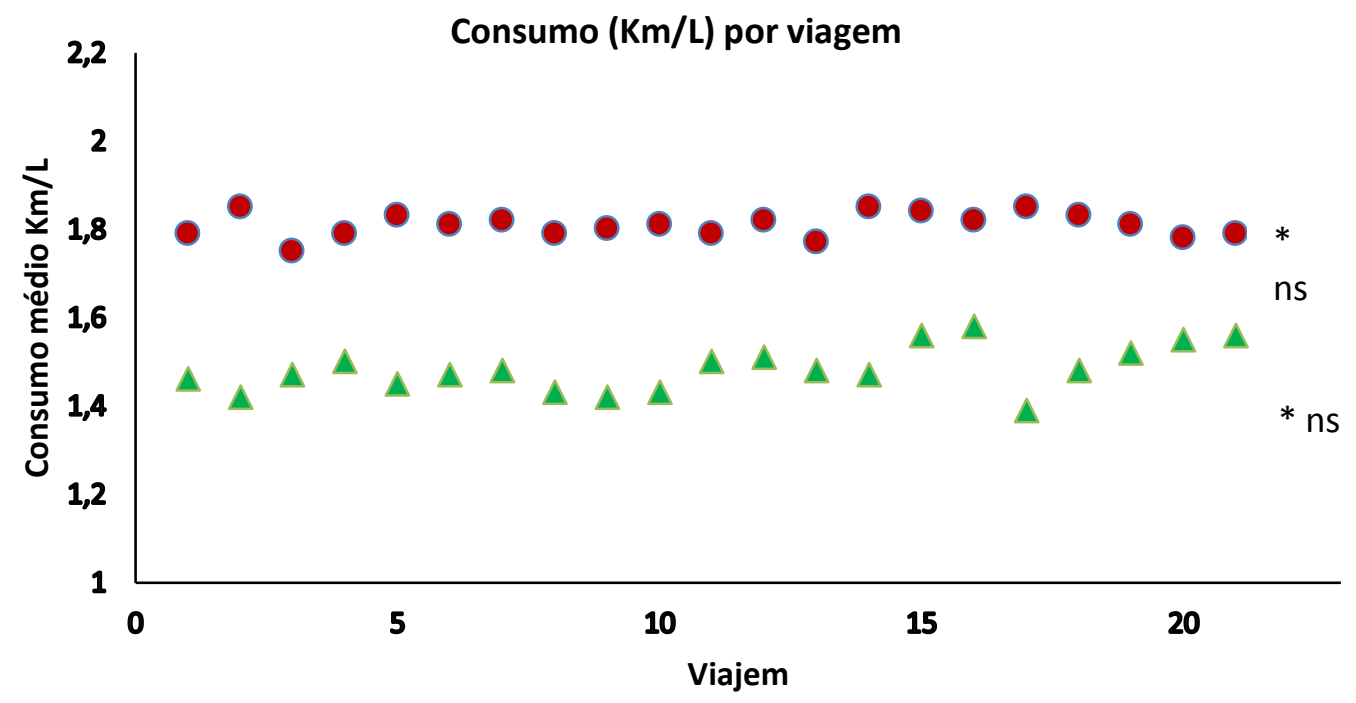

Patos de Minas MG - Santa Maria RS * ns P>0,05

$\triangle$ Patos de Minas MG - Fortaleza CE * ns $\mathrm{P}>0,05$

Fonte: Própria

Tabela 2 - Velocidade média e consumo de combustível para as duas rotas.

\begin{tabular}{ccccc}
\hline \multirow{2}{*}{ Viagem } & \multicolumn{2}{c}{ Patos de Minas - Santa Maria } & \multicolumn{2}{c}{ Patos de Minas- Fortaleza } \\
\cline { 2 - 5 } & $\begin{array}{c}\text { Vmed } \\
(\mathrm{Km} / \mathrm{h})\end{array}$ & Consumo $(\mathrm{Km} / \mathrm{l})$ & $\begin{array}{c}\text { Vmed } \\
(\mathrm{Km} / \mathrm{h})\end{array}$ & Consumo $(\mathrm{Km} / \mathrm{l})$ \\
\hline 1 & 67 & 1,79 & 63 & 1,46 \\
2 & 71 & 1,85 & 64 & 1,42
\end{tabular}




\begin{tabular}{lllll}
3 & 72 & 1,75 & 62 & 1,47 \\
4 & 69 & 1,79 & 65 & 1,50 \\
5 & 65 & 1,83 & 67 & 1,45 \\
6 & 69 & 1,81 & 68 & 1,47 \\
7 & 71 & 1,82 & 62 & 1,48 \\
8 & 70 & 1,79 & 63 & 1,43 \\
9 & 69 & 1,80 & 64 & 1,42 \\
10 & 69 & 1,81 & 62 & 1,43 \\
11 & 72 & 1,79 & 63 & 1,50 \\
12 & 71 & 1,82 & 61 & 1,51 \\
13 & 71 & 1,77 & 62 & 1,48 \\
14 & 72 & 1,85 & 64 & 1,47 \\
15 & 69 & 1,84 & 65 & 1,56 \\
16 & 69 & 1,82 & 63 & 1,58 \\
17 & 72 & 1,85 & 64 & 1,39 \\
18 & 72 & 1,83 & 67 & 1,48 \\
19 & 73 & 1,81 & 65 & 1,52 \\
20 & 71 & 1,78 & 63 & 1,55 \\
21 & 72 & 1,79 & 65 & \\
\hline
\end{tabular}

Fonte: Própria, 2018.

Tabela 3- Velocidade média e consumo de combustível para as duas rotas.

\begin{tabular}{lcc}
\hline \multicolumn{1}{c}{ Rota } & Velocidade média (Km/h) & Consumo (Km/L) \\
\hline Patos de Minas - Santa Maria & $69,95 \mathrm{a}$ & $1,76 \mathrm{a}$ \\
Patos de Minas- Fortaleza & $63,76 \mathrm{~b}$ & $1,48 \mathrm{~b}$ \\
\hline
\end{tabular}

Fonte: Própria, 2018.

${ }^{*} \mathrm{P}<0,05$ ANOVA mostrou diferenças significativas. Médias seguidas de mesma letra não diferem estatisticamente entre si, pelo teste de Tukey a $5 \%$ de probabilidade.

Os dados corroboram com Alamgir, et al (2017), que demonstrou que o estado de conservação das rodovias gera impactos econômicos, ambientais e sociais se comparados com rotas consideradas "Melhores" e "Piores". Segundo estudos de 2006 realizados por técnicos do Departamento Nacional de Estradas de Rodagem (DNER) e da Empresa Brasileira de Planejamento de Transportes (Geipot) publicados no catálogo da CNT (2006) ficou 
demonstrado que uma estrada em más condições de rodagem representa aumento de até $58 \%$ no consumo de combustíveis, de 38\% nos gastos de manutenção de veículo, de 50\% no índice de acidentes e de até $100 \%$ no tempo gasto nas viagens (Revista CNT, 2006). Portanto, considerando que a pesquisa demonstrou uma aumento de gasto de $9 \%$ a mais de combustível e tempo de viajem se compararmos com os índices da CNT (2006) poderíamos inferir que para as variáveis do estudo entre as duas rotas estudadas houvesse uma pequena melhora no quadro geral das estradas brasileiras, podendo ser um engano já que entre 2006 e 2018 houveram grandes avanços tecnológicos tanto na fabricação de motores para caminhões quanto para os combustíveis o que diminuiria o consumo por quilômetro rodado (Mercedes Benz, 2018).

No entanto, apesar dessa pequena melhora a pesquisa detectou que se considerarmos o preço médio do diesel em Patos de Minas que é de $\mathrm{R} \$ 3,548 /$ litro, a distância entre Patos de Minas a Fortaleza, que é de $2438 \mathrm{Km}$, e o consumo médio de 1,48 Km /l, o gasto total seria de $R \$ 11.689,22$ e portanto uma economia de $9 \%$ de combustível alcançaria $R \$ 1.052,03$. Se considerarmos que foram realizadas 21 viagens, então a economia total em 1 ano seria de $\mathrm{R} \$$ 22.092,63. Portanto, se a condição da pista entre Patos de Minas e Fortaleza fossem as ideais poderiam ser feitas quase duas viagens de ida e volta, a mais, apenas com a economia de combustível. Na outra rota, levando-se em conta o consumo no trajeto Patos de Minas Santa Maria de $1,76 \mathrm{~km} / \mathrm{l}$, seria possível com essa mesma economia rodar aproximadamente $10.959,14 \mathrm{~km}$, ou seja, realizar esse trajeto, que é de $1815 \mathrm{~km}$, por aproximadamente 3 viagens considerando ida e volta.

Além do consumo e da velocidade média, um fator que foi expressivo no que diz respeito à condição das estradas foram os defeitos encontrados nos pneus dos caminhões. Houve uma diferença estatística entre o número de pneus danificados em relação as rotas estudadas (Tabela 4), o que já era esperado, uma vez que todos os fabricantes de pneus não ofertam garantia em casos de acidentes devido à má conservação das estradas.

Tabela 4 - Número de Pneus danificados durante as 21 viagens para cada rota

Rota Pneus danificados

Patos de Minas Santa Maria $10 b$ 
Fonte: Própria, 2018.

*Médias seguidas de mesma letra não diferem estatisticamente entre si, maiúscula na coluna e minúscula na linha, pelo teste de Tukey a 5\% de probabilidade.

Os resultados (Tabela 5) demonstram que independentemente do trajeto os maiores danos aos pneumáticos estão caracterizados pela associação do peso da carga com a condição do pavimento. Verificou-se que existe uma diferença estatística na maioria dos defeitos apresentados nos pneus, que se devem ao fato de que há uma solicitação excessiva promovendo desgaste prematuro e perdas consideráveis.

Tabela 5 - Classe de danos aos pneumáticos.

\begin{tabular}{|c|c|c|c|c|}
\hline \multirow{2}{*}{ Grupo } & \multirow{2}{*}{ Defeitos apresentados } & \multirow{2}{*}{ Identificação do anexo I } & \multirow{2}{*}{$\begin{array}{l}\text { PM-SM } \\
\text { \% relatada }\end{array}$} & \multirow{2}{*}{$\begin{array}{l}\text { PM-F } \\
\text { \%relatada }\end{array}$} \\
\hline & & & & \\
\hline I & Perfurações & $1,2,13,14$ e 33 & $5 \mathrm{Cb}$ & $10 \mathrm{BC}$ \\
\hline II & $\begin{array}{l}\text { Danos por impactos } \\
\text { físicos }\end{array}$ & $3,7,13,15,16,21,22$ e 37 & $25 B$ & $15 B$ \\
\hline III & Excesso de carga & $5,17,18,25,26,29,30$ e 38 & $40 \mathrm{Aa}$ & $42 \mathrm{Aa}$ \\
\hline IV & $\begin{array}{l}\text { Problemas na } \\
\text { suspensão }\end{array}$ & $6,7,11,1219$ e 20 & $10 \mathrm{BCb}$ & $10 \mathrm{Bb}$ \\
\hline $\mathrm{V}$ & $\begin{array}{l}\text { Mal condução dos } \\
\text { veículos }\end{array}$ & $3,7,10,24,32$ e 34 & $10 \mathrm{BCb}$ & $9 \mathrm{Bb}$ \\
\hline VI & Condições ambientais & $3,8,9,35$ e 36 & $5 \mathrm{Cc}$ & $1 \mathrm{Cc}$ \\
\hline VII & $\begin{array}{l}\text { Problemas } \\
\text { fabricação }\end{array}$ & 3 e 12 & $5 \mathrm{Cb}$ & $13 \mathrm{BC}$ \\
\hline
\end{tabular}

Fonte: Própria, 2018.

PM-SM- Rota Patos de Minas MG a Santa Maria RS.

PM-F : Rota Patos de Minas MG a Fortaleza CE

*Médias seguidas de mesma letra não diferem estatisticamente entre si, maiúscula na coluna e minúscula na linha, pelo teste de Tukey a 5\% de probabilidade.

Os resultados demonstraram também que no grupo II, que diz respeitos aos danos por impacto, houve diferenças significativas entre as rotas estudadas. Foi verificado que essa modalidade de dano responde por $25 \%$ do prejuízo provocado durante as viagens e, em grande parte, ocasionados por buracos no asfalto, quinas em cabeceiras de ponte, pistas irregulares 
e na formação de monturos nos asfaltos provocados pelo excesso de carga agravado pelas estradas com estrutura mais frágil que o necessário além de asfalto de qualidade inferior.

Figura 3: Ilustração de alguns problemas nos pavimentos das rodovias
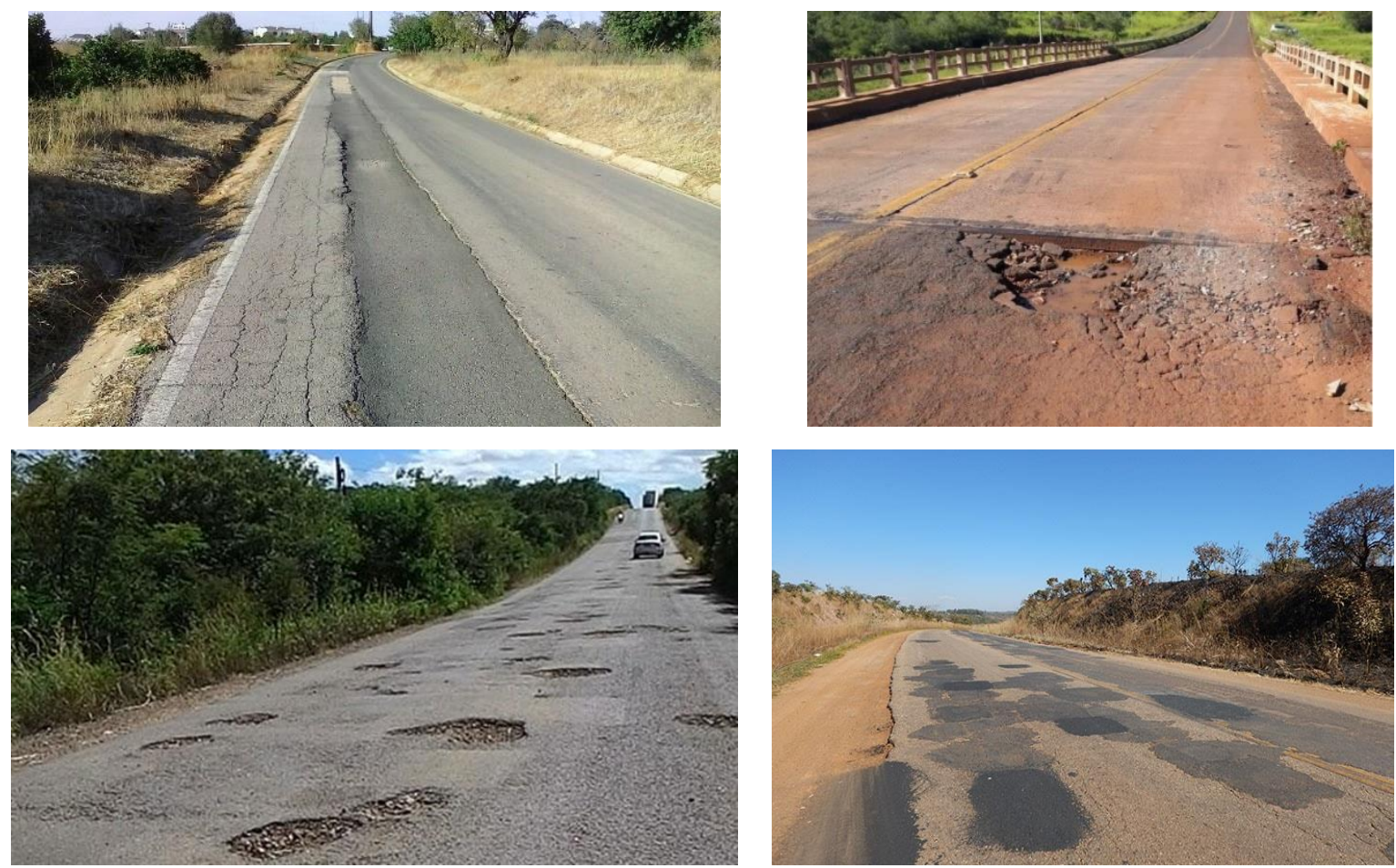

Fonte: Google.

Os danos causados por choques e impactos também acontecem durante a rodagem do pneu e se manifestam de forma instantânea, com ou sem perda da pressão. Eles se caracterizam por rupturas, estiramentos ou dobras provocadas por um contato violento do pneu contra um obstáculo, como: buracos, guias, desníveis de pista entre outros. Podem se apresentar como uma deformação provocada por uma ruptura dos cabos internos da carcaça ou das lonas de topo, que não são visíveis externamente. Outro problema bem comum dos impactos são os cortes no pneu que acontecem durante a rodagem e são provocados por asfaltos pontiagudos ou cortantes que deixam marcas claras e evidentes do seu causador. Podem atingir o interior do pneu e gerar uma perda de pressão ou podem ser superficiais sem perda de pressão o que depende bastante do tipo do modelo do pneu sendo os utilizados conforme Figura 4A e 4B. 
Figura 04A- Características técnicas de um pneu Pneu Goodyear Aro 17.5 Regional RHS 215/75R17.5 126/124L da fabricante Goodyear

\begin{tabular}{|c|c|c|c|c|c|}
\hline Medida & Quant de Lonas & $\begin{array}{c}\text { Indice de } \\
\text { Velocidade } \\
(\mathrm{km} / \mathrm{h})\end{array}$ & Durabilidade & Tipo de pneu & Carga máxima \\
\hline $215 / 75 \mathrm{R} 17.5$ & 16 & variável $^{1}$ & $80000 \mathrm{Km}^{2}$ & SC & Variável $^{3}$ \\
\hline
\end{tabular}

Fonte: Site da fabricante Goodyear.

1-É variável de acordo com uma tabela de variação de carga em função da velocidade podendo haver um incremento ou diminuição de acordo com os dados utilizados.

2- estimada

3- De acordo com a tabela 4B

Figura 4B- Pressão de inflação x carga

\begin{tabular}{cccccccccc} 
& \multicolumn{8}{c}{ Pressão de inflação $-\mathrm{lb} / \mathrm{pol}^{2}$ ( bar) } \\
\cline { 2 - 9 } & 70 & 75 & 80 & 85 & 90 & 95 & 100 & 105 & 110 \\
& 4.8 & 5.2 & 5.5 & 5.8 & 6.2 & 6.5 & 6.9 & 7.3 & 7.6 \\
\hline Modelo & & \multicolumn{7}{c}{ Carga por pneu (Kg) } \\
\hline 124 & 1600 & 1750 & 1850 & 1980 & 2060 & 2135 & 2300 \\
126 & 1800 & 1950 & 2060 & 2170 & 2240 & 2340 & 2520 & 2600 & 2725 \\
\hline
\end{tabular}

Fonte: Site da fabricante Goodyear.

Um corte pode não ter consequências imediatas no desempenho do pneu. No entanto, com os diversos movimentos e solicitações sob os quais o pneu é submetido ao longo da sua vida útil, o corte pode evoluir e provocar uma perda brusca de pressão e dificuldades no controle do veículo, aumentando-se o risco de acidentes. Em alguns casos, também pode provocar a oxidação das lonas do pneu, ocasionando a ruptura da estrutura interna. Toda deformação no pneu deve ser examinada por um profissional especializado e, caso seja proveniente de um dano, o pneu deve ser retirado de uso imediatamente, pois esta deformação irá evoluir com o uso até provocar a perda instantânea da pressão e do controle do veículo.

Além dos problemas com impacto, outro grupo que chamou a atenção foram os defeitos do grupo VI, aqueles ocasionados pela fabricação dos pneus. Observou-se que na rota Patos de Minas-Santa Maria ocorreram maiores perdas sendo uma das explicações prováveis é que a duração média dos pneus de carga originais é de $80000 \mathrm{~km}$ e de ressolados $75000 \mathrm{~km}$, o que faz com que seja justificável o uso do pneu que foi recondicionado em detrimento ao original. A velocidade média maior é conseguida pelo fato de melhor ritmo durante a viagem e com as altas temperaturas do nosso país associada a grande carga pode promover uma 
maior perda de pneus devido a perda da recapagem utilizada. Não existem estudos recentes e técnicos que faça a ligação direta entre o uso do pneu original se comparado ao ressolado com o passar dos anos e o aumento da tecnologia de recapagem, porém a relação custo/benefício é maior deste em relação aquele uma vez que a durabilidade de rodagem é praticamente a mesma, no entanto, espera-se que não exista a mesma segurança do ressolado em relação ao original o que é claramente visto nas rodovias através da quantidade de bandas de rodagem ao longo das estradas brasileiras. Apesar da aparente insegurança que poderia promover ao motorista não é constatado tal afirmação, o que segundo eles não acontece devido ao fato de que diferentemente dos veículos pequenos o conjunto de rodagem é muito numeroso, sendo que a perda de um pneu algumas vezes pode ser contornada.

Tal afirmação não é totalmente verdadeira por parte dos caminhoneiros uma vez que se analisarmos nesta época do ano, com chuvas constantes, o número de buracos nas ruas e rodovias aumenta consideravelmente, assim como os atendimentos nas oficinas e o número de acidentes. $O$ custo do conserto dos danos causados por buracos varia bastante. No entanto, não houve diferença estatística entre as rotas, apesar de ter uma pequena variação matemática e isso pode estar ligado ao fato de que as chuvas atrapalham a visibilidade e aumentam os problemas devido à má conservação das estradas.

Do ponto de vista financeiro percebeu-se que os custos com frete, no modal rodoviário, apresentam um complicador que independentemente da rota o cálculo do valor do transporte tem se tornado cada vez mais caro e mais difícil de ser determinado devido a complexidade de variáveis. Percebe-se que o problema vem se arrastando há vários anos, pois um país do tamanho territorial do Brasil já deveria ter iniciado uma mudança em seu modal de transporte para hidroviário ou ferroviário. Haveria uma redução de custos de $44 \%$ em relação ao ferroviário e de $84 \%$ frente ao hidroviário. Sabe-se, logicamente, que não seria possível possuir apenas o transporte hidroviário ou ferroviário mas para diversos autores estima-se que os trajetos rodoviários não deveria exceder cerca de $300 \mathrm{~km}$ completando apenas as pontas das linhas quer seja rodoviário ou ferroviário (Azambuja, et al. 2015; Fiesp, 2016). Pesquisa recentes (Centro de Estudos em Logística - CEL et al., 2017) apontam que 61\% da matriz ainda são transportadas por rodovias, $21 \%$ por ferrovias e $18 \%$ por hidrovias e que os custos mantiveram a proporcionalidade demonstrada por Afonso (2006). 


\section{CONCLUSÕES}

O estudo indicou que a má conservação das rodovias impacta diretamente a economia dos caminhoneiros e transportadoras. Além disso, não somente impacta de forma negativa a economia própria, como gera um processo de "anti-economia", ou seja, caso não haja investimentos na manutenção da malha rodoviária os gastos e perdas gerados poderão resultar em perdas financeiras futuras que impactarão toda a economia do país tanto em manutenção de veículos como na própria reconstrução das estradas.

Pensando que o combustível utilizado nos caminhões é o diesel, um consumo de $9 \%$ a mais além de gerar uma anti economia fere gravemente a sustentabilidade ambiental se pensarmos na emissão de poluentes e no volume maior de retirada de um recurso finito como é o caso do petróleo, situação está potencializada pelo maior tempo de viajem exigindo mais caminhões criando um ciclo perverso.

Após a possibilidade de verificar a relação direta entre as variáveis estudadas no trabalho acredita-se que algumas atitudes devem ser tomadas tais como investimentos consideráveis na malha ferroviária e hidroviária, diminuição do uso de transporte de cargas por rodovias, melhoria da malha rodoviária existente e maior preocupação com questões ambientais.

\section{REFERENCIAL BIBLIOGRÁFICO}

ALAMGIR, M., CAMPBELL, M. J., SLOAN, S., GOOSEM, M., CLEMENTS, G. R., MAHMOUD, M. I., \& LAURANCE, W. F. (2017). Economic, Socio-Political and Environmental Risks of Road Development in the Tropics. Current Biology, 27(20), R1130-R1140. https://doi.org/10.1016/j.cub.2017.08.067

AFONSO, H. C. A. da G. Análise dos custos de transporte da soja brasileira. 2006. Tese de Mestrado (Engenharia de Transportes) - Instituto Militar de Engenharia, Rio de Janeiro. 138p.

AZAMBUJA, A. M. V., M. S. OliVEIRA, \& M. L. P. LIMA. (2015). Aplicação do Modelo de Análise de Janelas DEA em Terminais de Contêineres Brasileiros. Journal of Transport Literature, 9 (4), 25-29. [ Links ]

CNT. Confederação Nacional dos Transportes. Transportes de cargas no Brasil. Centro de Estudos em Logística - COPPEAD, 2002. Disponível em: htpp.<www. cnt.org.br>. Acesso em: 04 Jan de 2006.

CENTRO DE ESTUDOS EM LOGÍSTICA (CEL); CONFEDERAÇÃO NACIONAL DOS TRANSPORTES (CNT). Transporte de carga no Brasil: ameaças e oportunidades para o desenvolvimento do país. Rio de Janeiro, set. 2017. Disponível em: <http://www.coppe.ufrj.br>. Acesso em: janeiro. 2018. 
CONFEDERAÇÃO NACIONAL DOS TRANSPORTES (CNT). Boletim econômico. Brasília, jan. 2017. Disponível em: <http://www.cnt.org. br/cnt/downloads/becon/BeconCNT012006.pdf>. Acesso em: 22 jan. 2018.

FIESP - FEDERAÇÃO DAS INDÚSTRIAS DO ESTADO DE SÃO PAULO. Conceito de logística. Brasília: Fiesp, 2016. Disponível em: <http://www.fiesp.com.br/transporte-elogistica/>. Acesso em: outubro de 2018.

GOOGLE MAPS. Rotas estudadas. Disponível em:

https://support.google.com/maps/answer/144339?co=GENIE.Platform\%3DDesktop\&hl=pt-BR. Acesso 10 julho 2018.

MERCEDES BENZ. Centro de Estudos de Motores e Tecnologia. São Paulo, 2018. Disponível em:

https://www.mercedes-benz.com.br/caminhoes. Acesso em outubro de 2018.

VIPAL. Guia de danos e desgaste. Cadernos Técnico. Lajeado RS, 2016.

UOL. Revista eletrônica Caderno de Economia. São Paulo 2018. Disponível em : https://economia.uol.com.br/noticias/efe/2018/09/20/sem-investimentos-50-das-estradas-do-pais-estaraoem-mas-condicoes-ate-2025.htm. Acesso em outubro de 2018. 
ANEXO 1- Guia de danos aos pneumáticos

1.Penetração de objeto durante o percurso

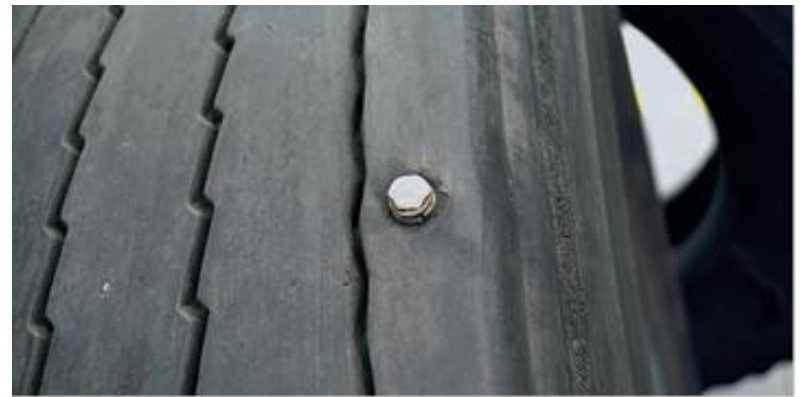

3. Separação no flanco/lateral em pneus radiais

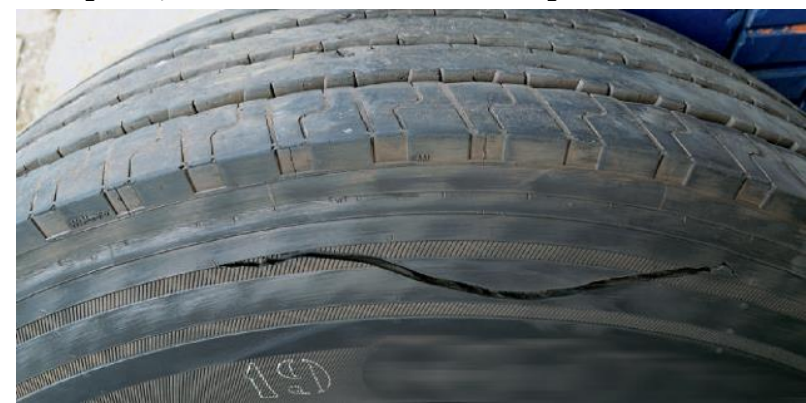

5. Separação da borracha do flanco em pneus radiais

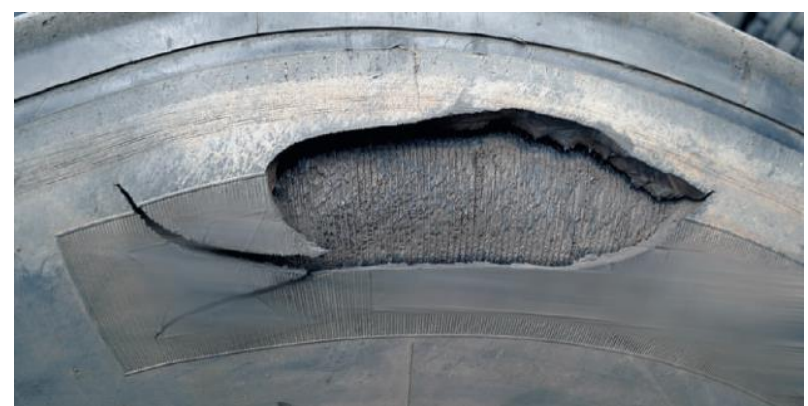

7.Separação na região do ombro

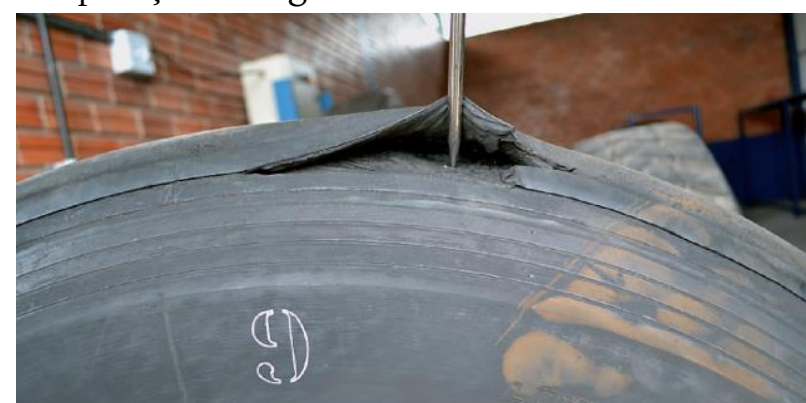

9. Excesso de cortes na banda de rodagem
2. Dano por infiltração

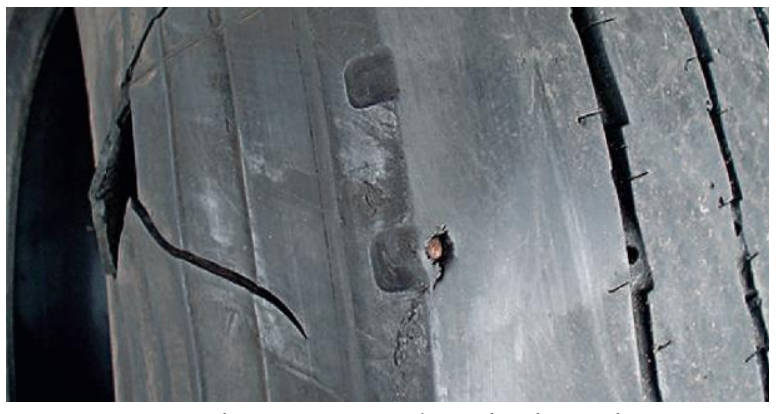

4. Separação das cintas na banda de rodagem

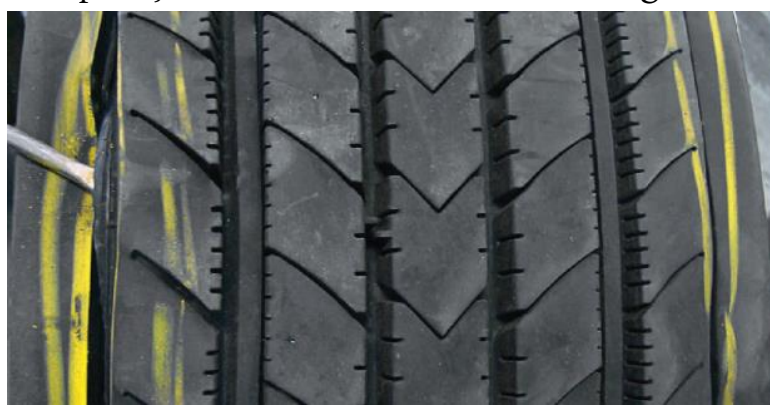

6. Exposição das extremidades das lonas/cintas

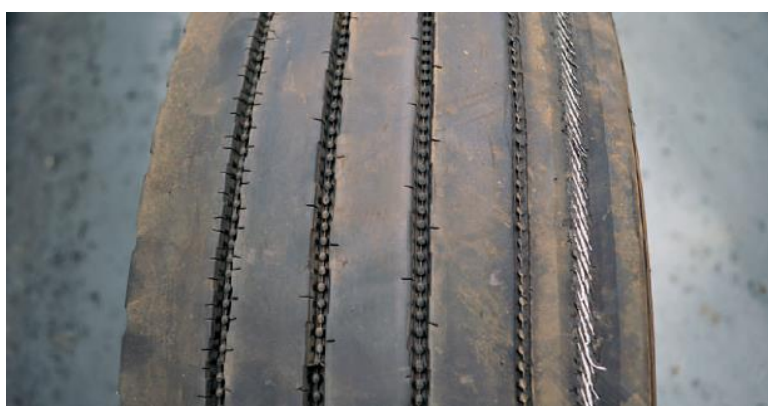

8. Desagregação da banda de rodagem

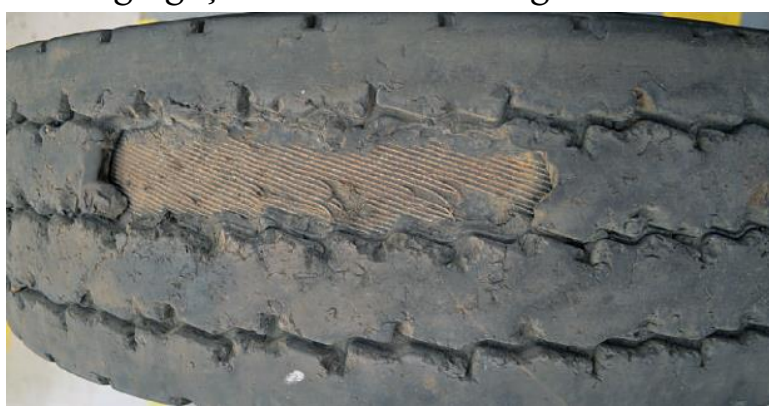

10. Roçamento na banda de rodagem 


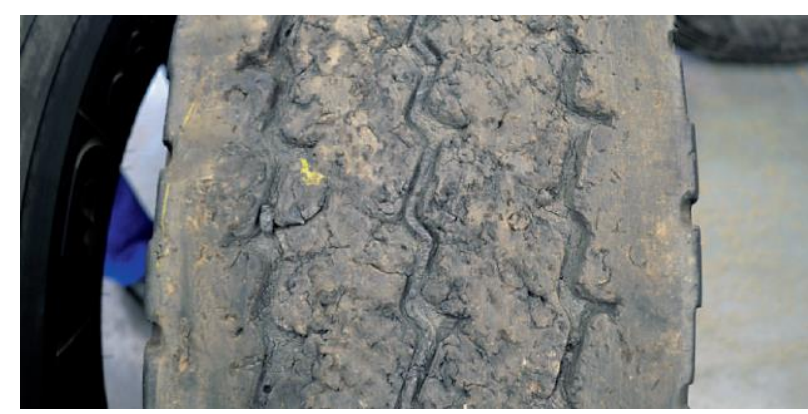

11. Roçamento lateral do pneu

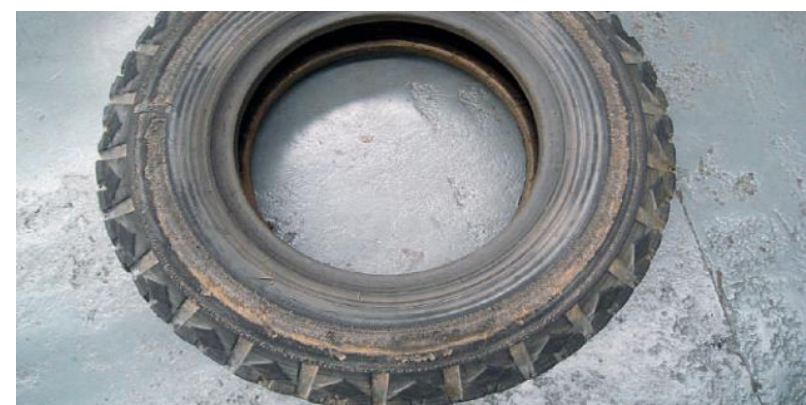

13. Contaminação do pneu

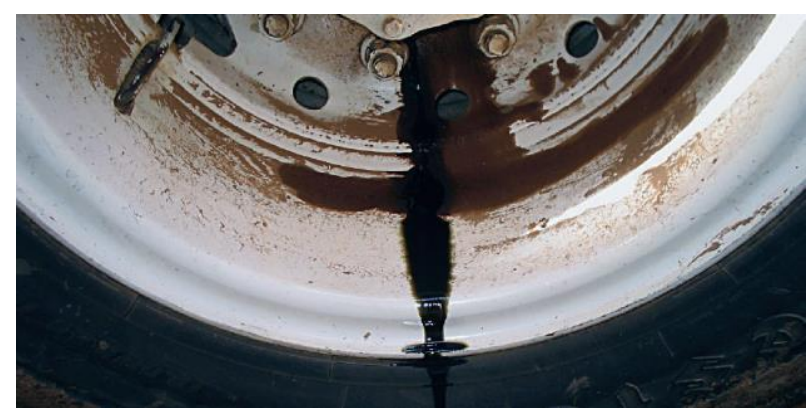

15. Deformação (saliência) no flanco do pneu radial

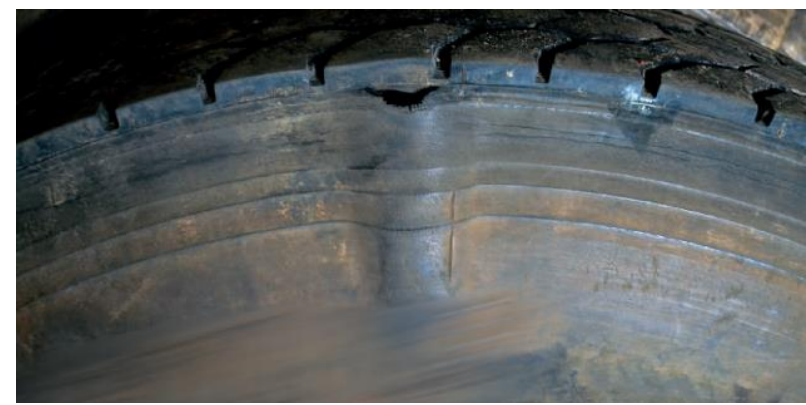

17. Danos no talão

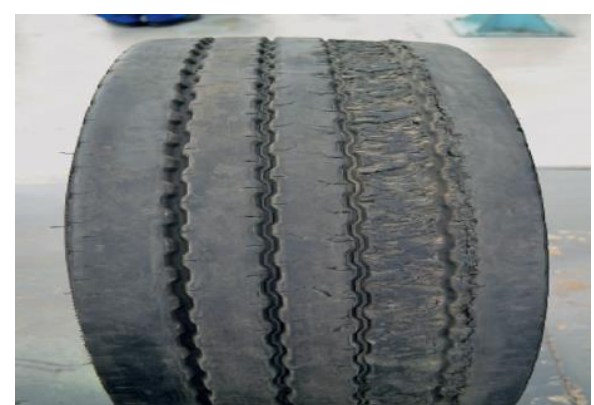

12. Arrancamento de parte da banda de rodagem (ribe)

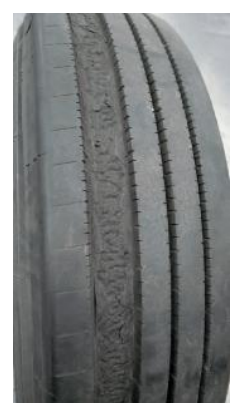

14. Separação região do ombro em pneu diagonal

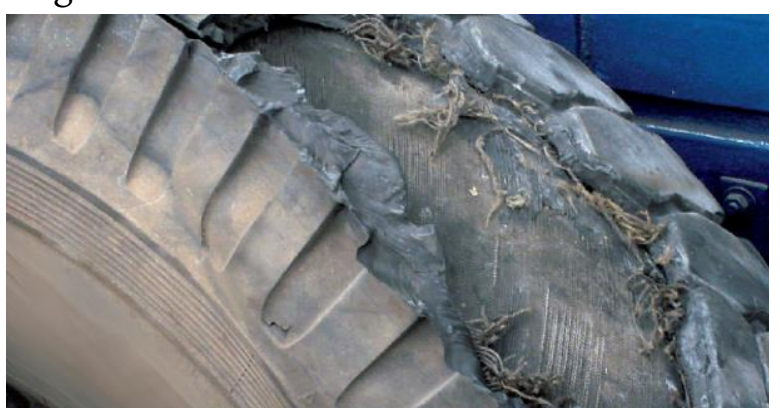

16. Rachadura circunferencial nos talões dos pneus radiais

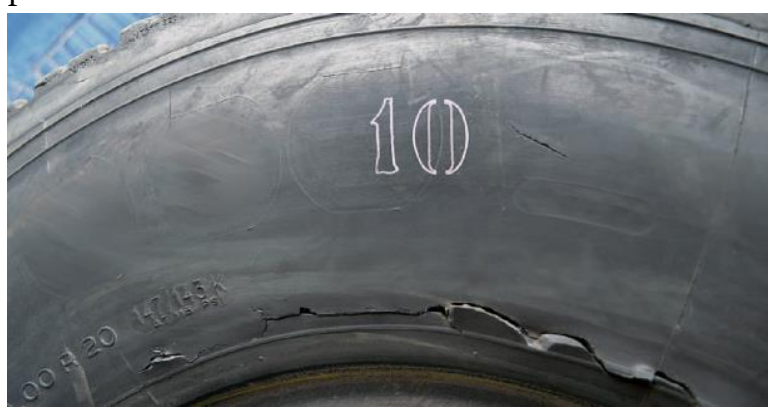

18. Desgaste diagonal 


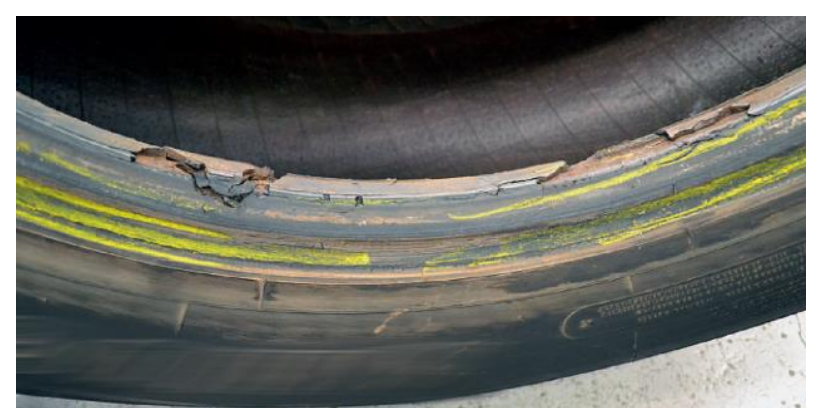

19. Desgaste assimétrico

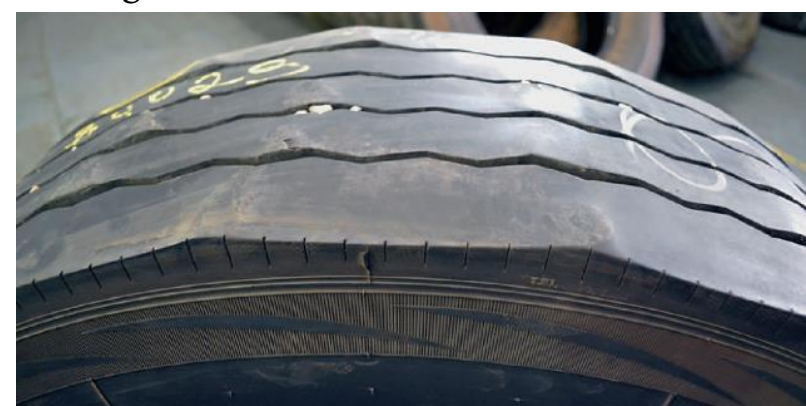

21. Rachadura radial no flanco

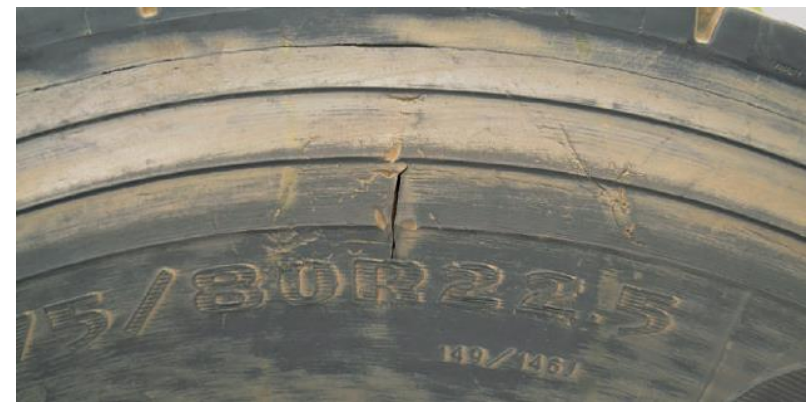

23. Ruptura lateral em pneus radiais

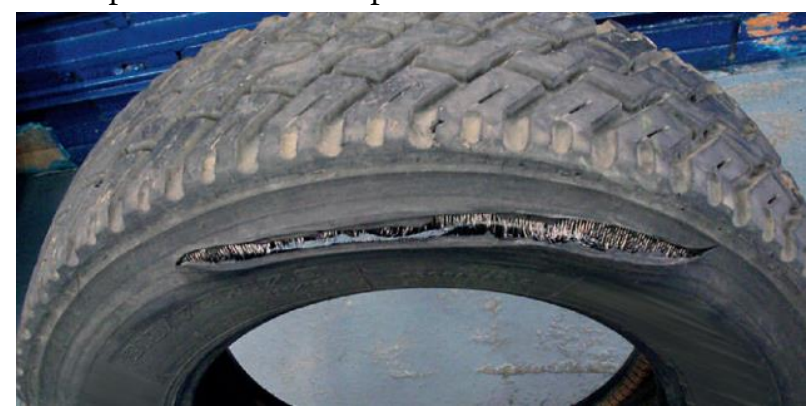

25. Rachadura na banda de rodagem pneus diagonais

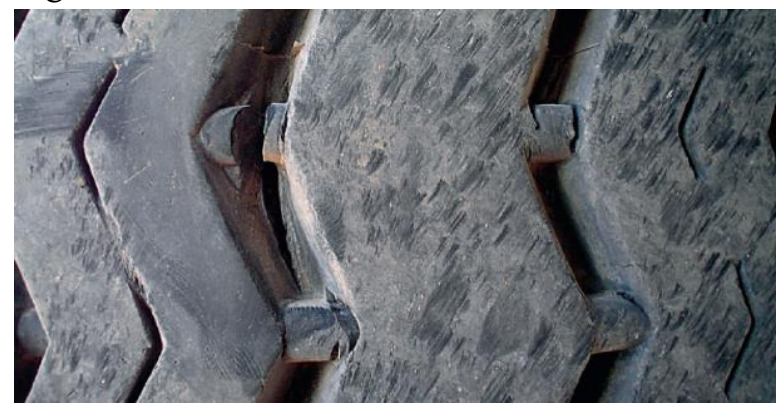

27. Dano localizado

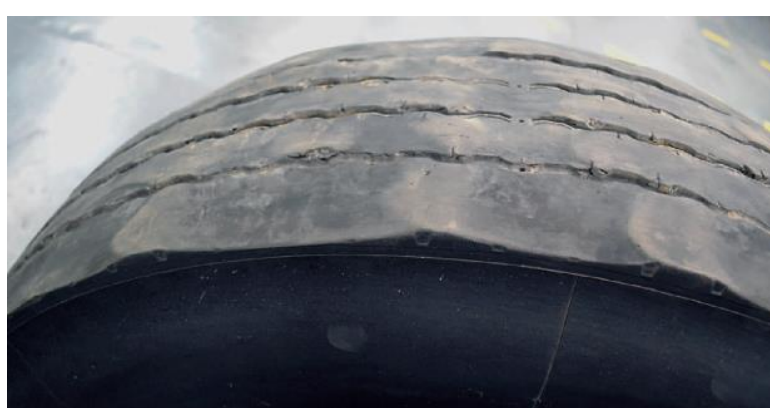

20. Dano no flanco

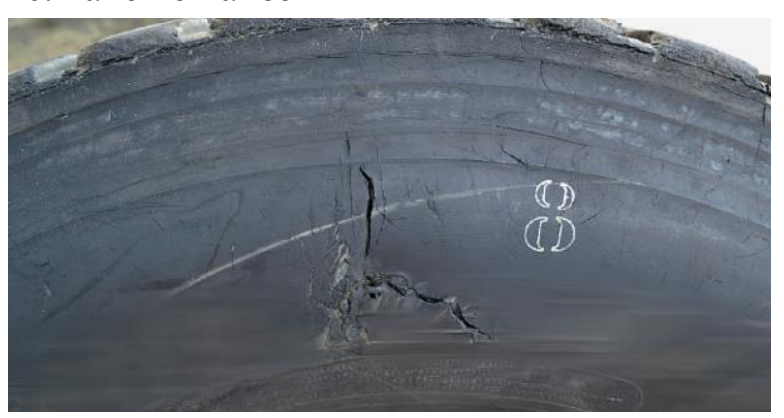

22. Dano acidental no flanco

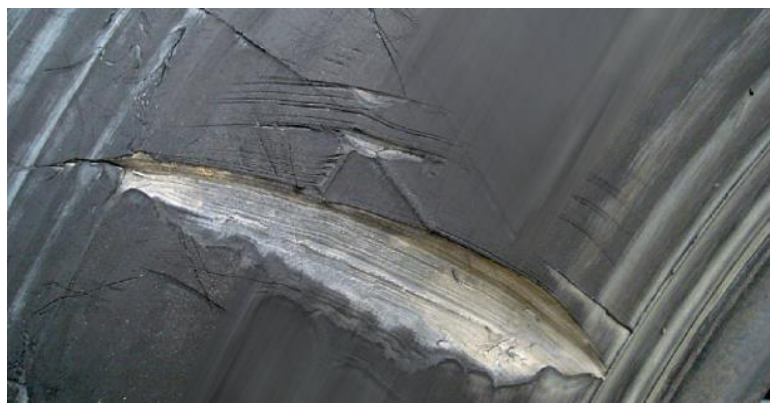

24. Ruptura circunferencial

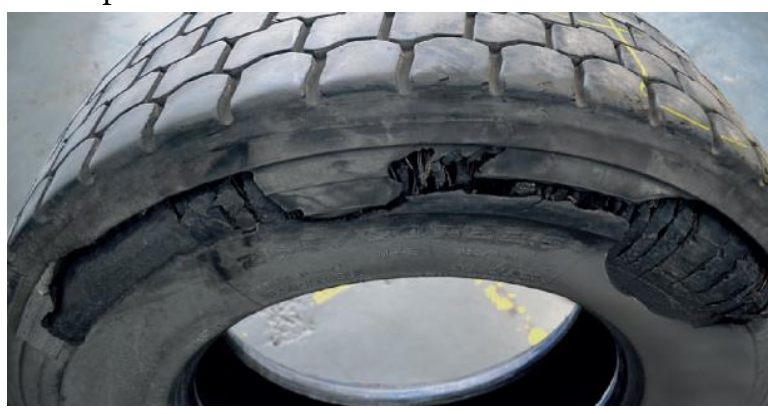

26. Picotamento na banda de rodagem

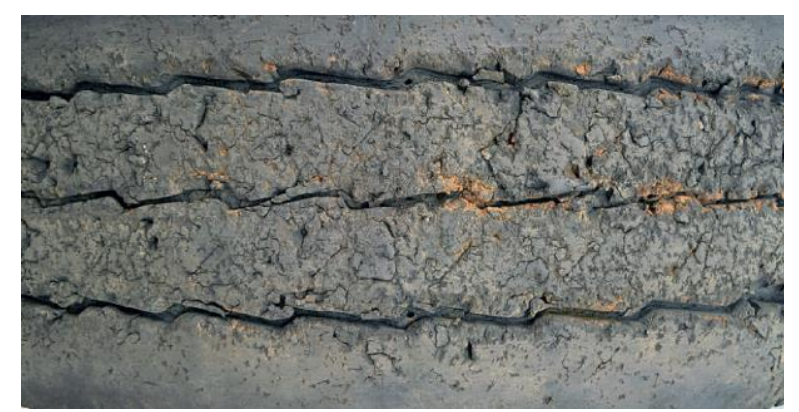

28. Dano interno 


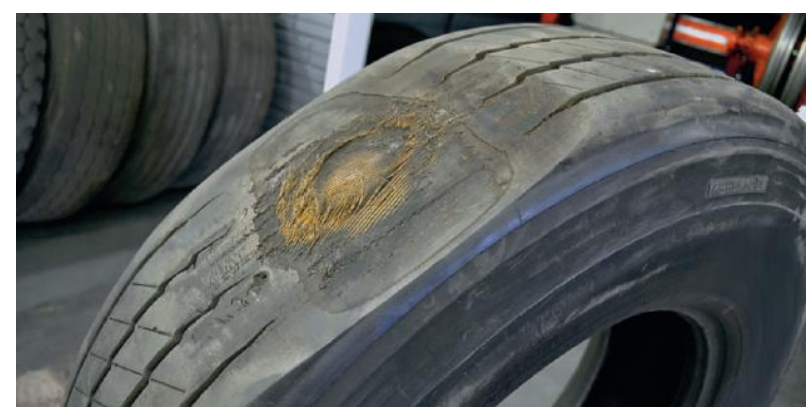

29. Desgastes nos ombros da banda de rodagem

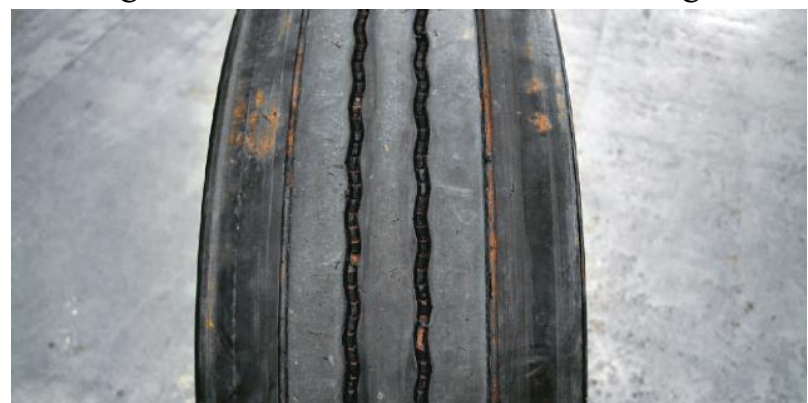

31. Arrancamentos de blocos

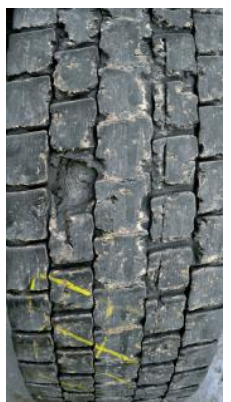

33. Desgaste irregular nos blocos

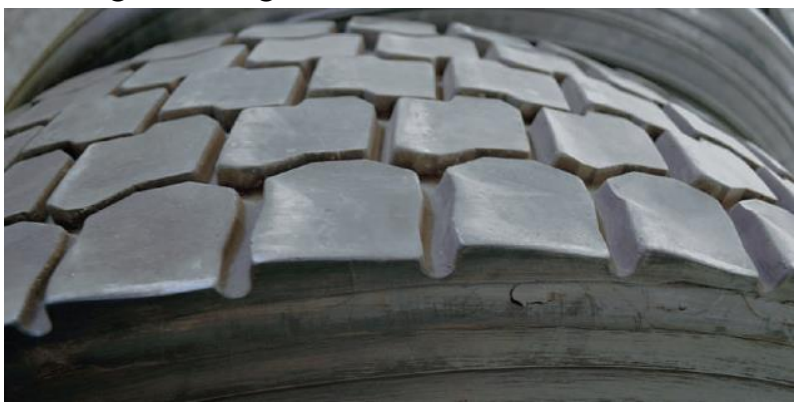

35.Talão queimado

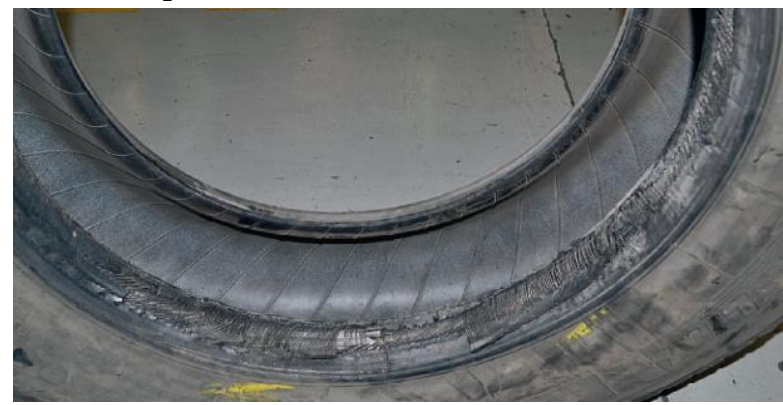

37. Desgaste acentuado em um dos ombros do pneu

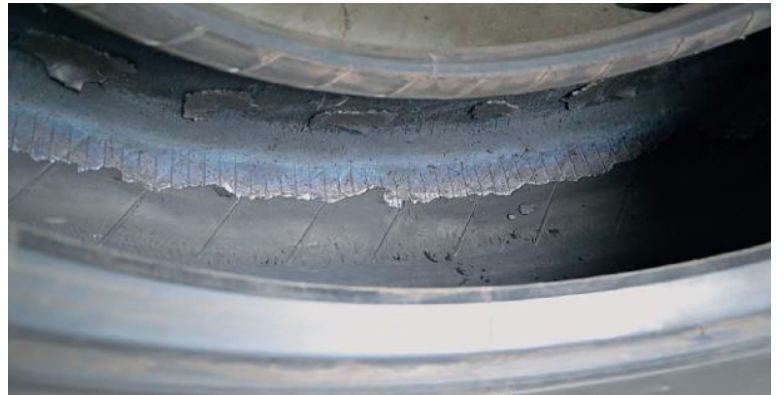

30. Desgaste centralizado

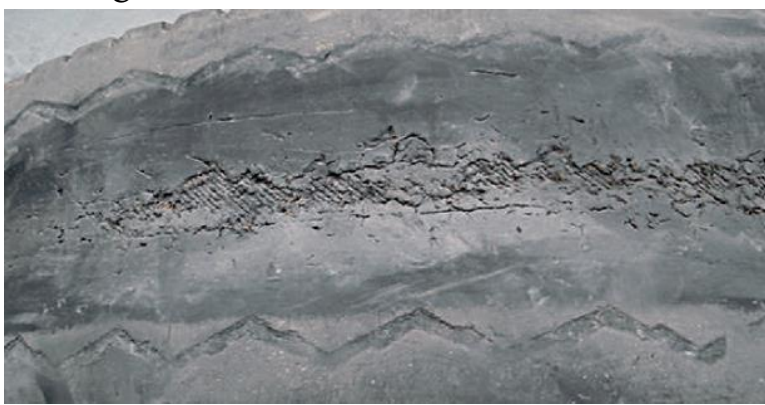

32. Corte na banda de rodagem

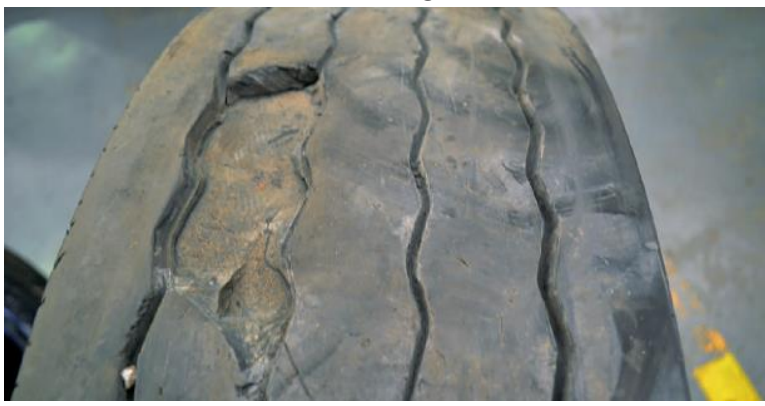

34 Rachaduras/trincas na lateral do pneu

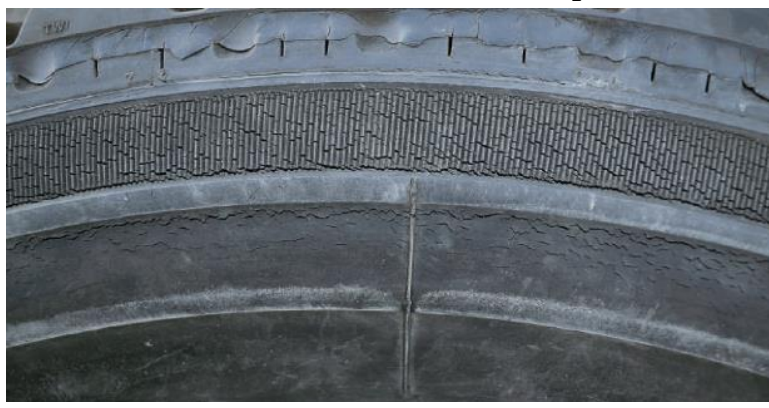

36. Ruptura radial do pneu

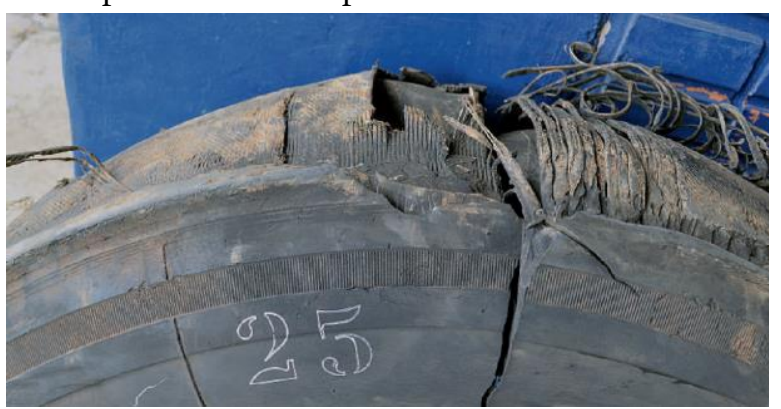

38. Dano no ombro 

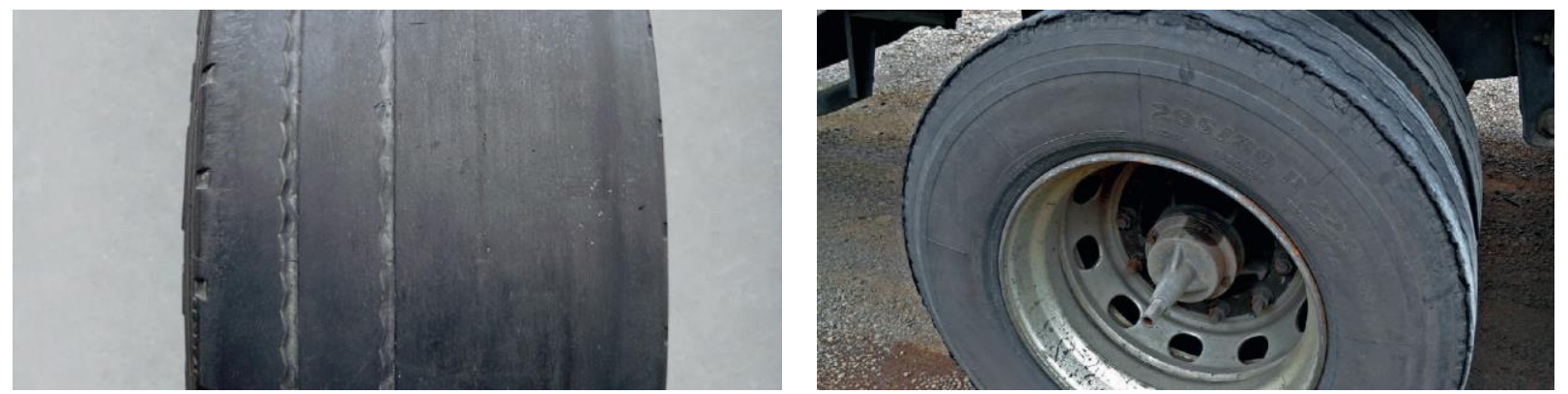

Fonte: Guia de Danos e Desgastes Vipal BV-C-Po\#330B, 2016.

\section{(cc) EY}

Este trabalho está licenciado com uma Licença Creative Commons - Atribuição 4.0 Internacional. 